\title{
Experimental and Analytical Investigation of Drilling on GFRC Material for Enhancement of Drilling Quality: A Review
}

\author{
G. S. Tate ${ }^{1}$, A. M. Shaikh ${ }^{1}$, V. S. Mane ${ }^{2}$ \\ ${ }^{\text {I}}$ Production Engineering Department, K. B. P. College of Engineering, Satara, Shivaji University, India \\ ${ }^{2}$ (Department of Mechanical Engineering, M. E. S. College of Engineering, S. P. Pune University, India)
}

\begin{abstract}
A composite material is made out of a mixture or a combination of two or more distinctly differing materials which are insoluble in each other and differ in form or chemical composition. The machining of composite materials is a growing problem in various fields such as aeronautical, automotive, wind turbine industries. In particular, the drilling of these materials, required to assemble different parts, is difficult to control and often leads to delamination at the exit of the laminates. This paper aims at the comprehensive analytical and experimental investigation work done on the drilling on GPRP composites material. The conclusion of the paper discusses the development and outlines the trends for the research in this field.
\end{abstract}

Keywords: Drilling on GFRP, Delamination, Surface Roughness, Design of Experiment, Taguchi Analysis

\section{Introduction}

Engineering materials are changing faster and the choice is wider than ever before. This is mainly because of the expansion in materials, processes, and computational abilities. Advanced high - tech industries adopted new materials and processes; replacement of mild steel with high strength steel, lighter non - ferrous alloys, such as aluminium and magnesium alloys, plastics, and composites. Many industries developing high strength, low weight materials for wide applications such as composite materials [1,2]. A composite material can be distinct as a mixture of a matrix and a reinforcement, which when combined gives properties higher to the properties of the individual components. In the case of a composite, the reinforcement is the fibres and is used to fortify the matrix in terms of strength and stiffness. The reinforcement fibres can be cut aligned placed in different ways to affect the properties of the resulting composite. The matrix, normally a form of resin, keeps the reinforcement in the desired orientation. It protects the reinforcement from chemical and environmental attack, and it bonds the reinforcement so that applied loads can be effectively transferred. The technological and commercial interest in composite material lies in their superior properties of strength-to-weight, stiffness-toweight, fatigue and thermal expansion compared to metals. Extensive use of composite in application such as rockets, satellites, missiles, light combat aircraft, advanced light helicopter and trainer air craft has shown that India is on par with the advanced countries in the development and use of composites in this area [3]. The machining of composite materials is a growing problem in various fields such as aeronautical, automotive, wind turbine industries. In particular, the drilling of these materials, required to assemble different parts, is difficult to control and often leads to delamination at the exit of the laminates. This can affect the strength of the structure.[4] This paper involves study on experimental and analytical investigation of drilling on Glass fibre reinforced plastic material. GFRP mostly used in the industries due to their high mechanical properties such as high strength-to-weight and stiffness-to-weight ratios. Our objective is to reduce delamination of GFRP work piece by selecting process parameters and tool parameters. By selecting suitable ranges of the parameters as per the convenience and by selecting the drilling machine as per availability we made the drilled holes. Inspecting the drilled holes on tool makers' microscope, analysis of delamination factor for each drilled hole was done. By comparing the delamination factor of various drill holes we found the suitable range of parameter in which the delamination was least. By improving the quality of drill we can improve the life of the work piece $[5,6]$

\section{Delamination Theory}

Delamination is a critical failure mechanism in laminated fiber-reinforced polymer matrix composites, and is one of the key factors differentiating their behavior from that of metallic structures. It is caused by high inter laminar stresses in conjunction with the typically very low through-thickness strength. The phenomenon arises because fibers lying in the plane of a laminate do not provide reinforcement through the thickness, and so the composite relies on the relatively weak matrix to carry loads in that direction. This is compounded by the fact that matrix resins are typically quite brittle. Delamination failure may be detected in the material by its sound. Fig. 1 shows the delamination in the entry and exit of the material. 


\section{1 Delamination Factor $(\mathbf{F d})$}

It is the ratio of maximum diameter obtained to the diameter of the drill

$$
\mathrm{Fd}=\frac{D \max }{D d r i l l}
$$

In which, Dmax is the maximum diameter of the delamination zone in $\mathrm{mm}$ Ddrill is diameter of the drill in $\mathrm{mm}$.

Fig. 2 shows the geometry of drilling hole in which we can observe the delamination factor
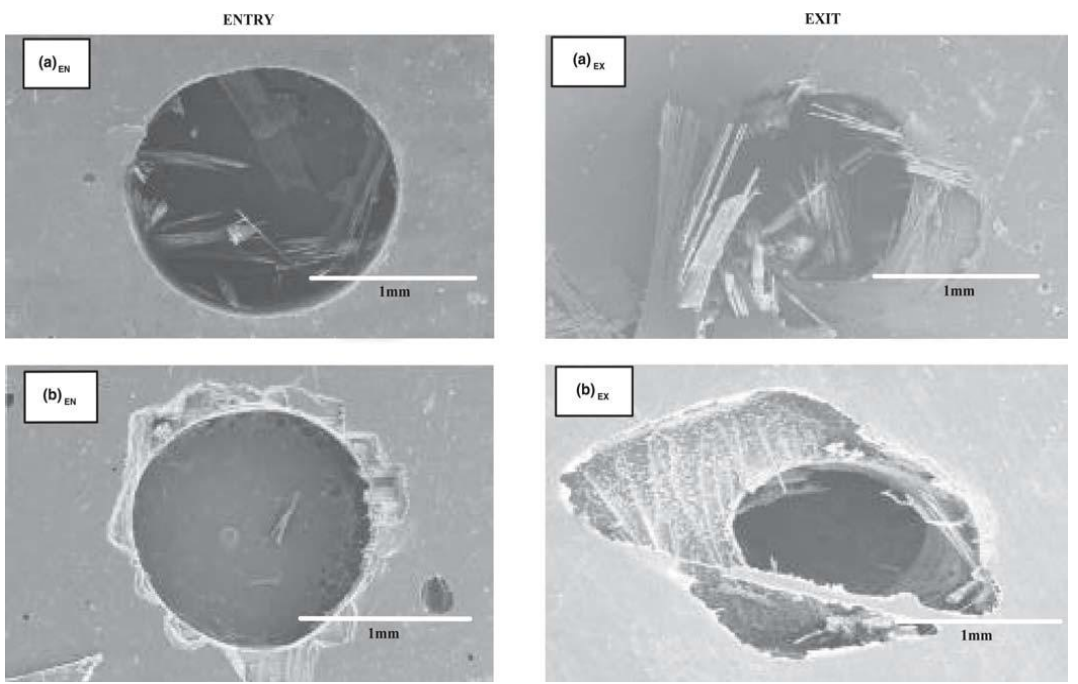

Fig. 1: Delamination

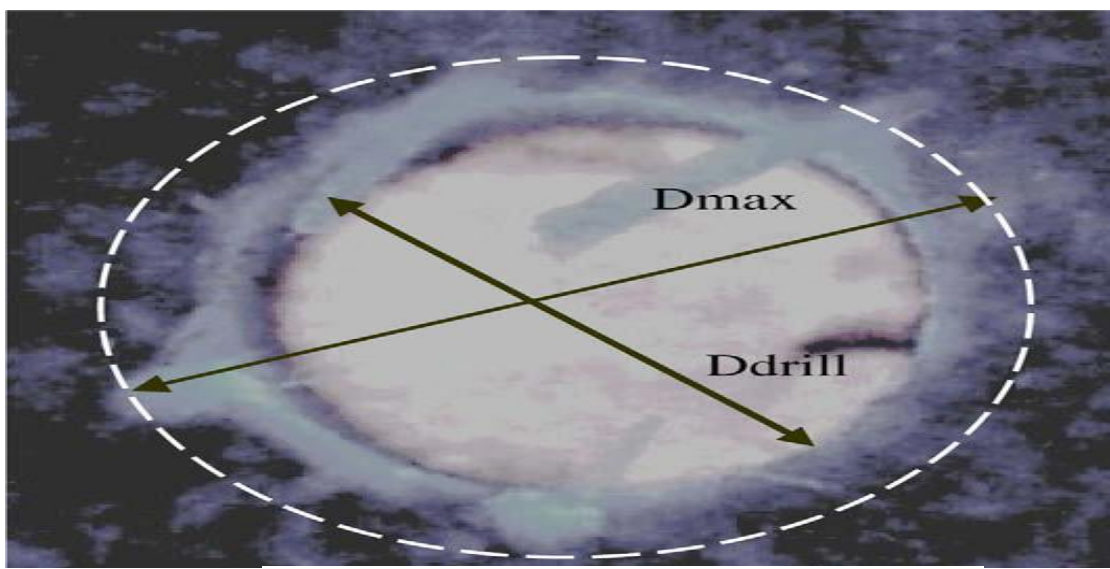

Fig. 2. Illustration of delamination size on drill hole

\section{Drilling of GFRP Composites}

S. Arul et al. [9] investigated the effect of tool material on dynamics of GFRP composites. Drilling trials have been carried out on glass fiber reinforced plastics (GFRP) with plain high speed steel (HSS), TiN coated HSS and tipped tungsten carbide drills. Found that most of the defects in drilling of composites are due to thrust force experienced by the workpiece. They done thrust modeling (evaluation of critical thrust) and founded out effect of tool material on thrust, effect of tool material on flank wear, effect of tool material on hole shrinkage and delamination factor. Fig. 3 illustrated the relative hole quality between the tool material. It can be seen that the stress whitening layer around the exit of the hole increases with the number of holes drilled. As seen in figure, lower order shrinkage can be seen in the case of the tipped tungsten carbide drills. In drilling with HSS and TiN coated HSS, increases of thrust and delamination factor around 30 holes, indicate that 30 is the limiting number of holes to be drilled while with cemented tungsten carbide drill 50 is the limiting number of holes to be drilled for defect tolerancing. Coating of drills does not give much improvement in drilling 
performance. Tipped carbide drills performed better than HSS. Birhan Isik et al. [10] presented a new comprehensive approach to select cutting parameters for damage factor in drilling of glass fiber reinforced polymer (GFRP) composite material. The influence of drilling on surface quality of woven GFRP plastic composite material was investigated experimentally. Damage factor was investigated based on hole entrance and exit. Deformation at the hole entrance and exit were observed by MITUTOYO TM-500 digital indicator microscope. Damage factor (DF) was determined by the ratio of maximum deformation diameter to the hole diameter. Analysis of variance (ANOVA) test was applied to the experimental results. From the experiment they resulted as increasing of cutting speed increases DF at both hole entrance and exit. Increasing of feed increases DF at hole exit and decrease DF at hole entrance. Increasing of point angle increases DF at both hole entrance and exit. Delamination, chipping and spalling damage mechanism were observed in drilling chopped and continuous winding composites. Figure 4 illustrate the Peel-up and Push-up delamination at entry and exit of the drilling of FRP laminates.

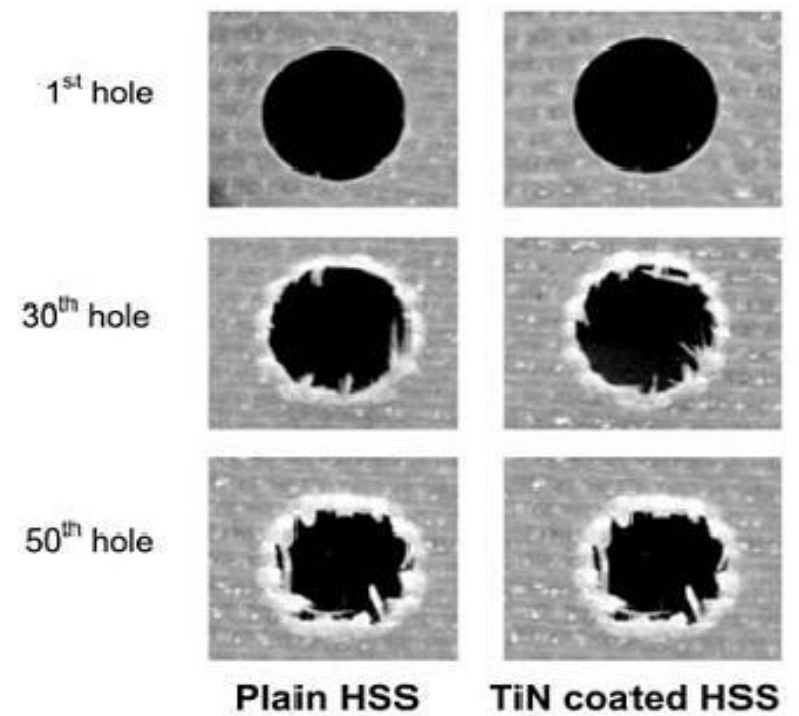

Fig. 3: The relative hole quality [9]
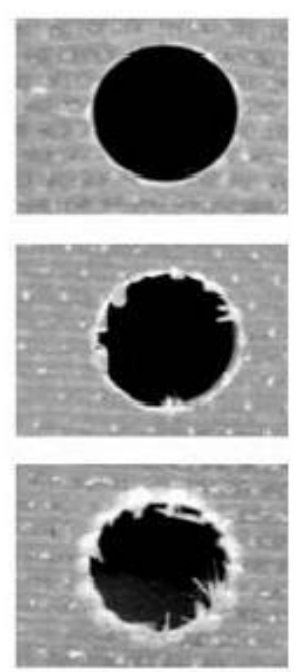

Tipped WC

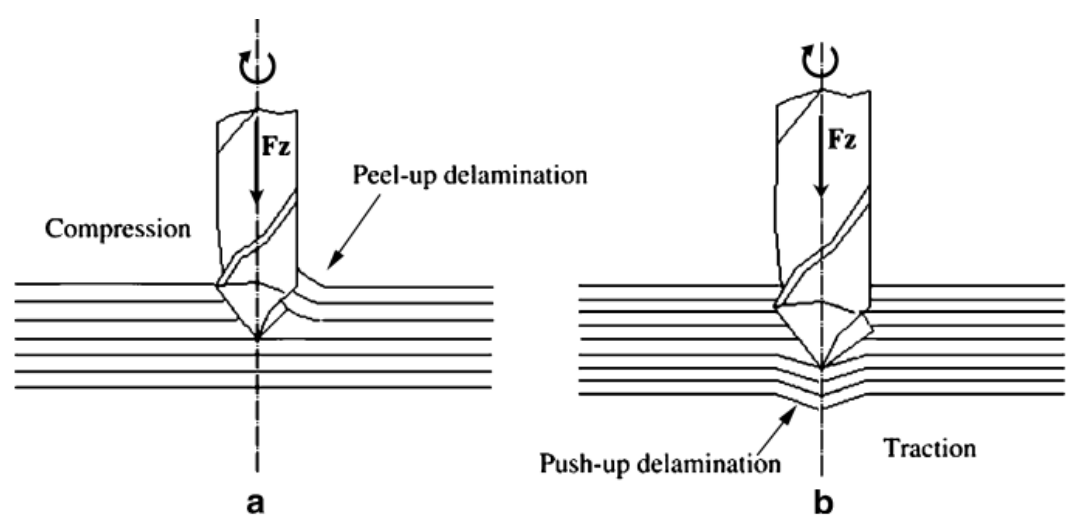

Fig. 4: Delamination at hole entrance (a) and exit (b) when drilling FRP laminates [10]

J. Campos Rubio et al. [11], worked on High speed machining to realize high performance drilling of glass fiber reinforced plastics (GFRP) with reduced damage. Results presented suggest that the adjusted delamination factor is more sensitive to the machining parameters (spindle speed and feed rate) than the conventional delamination factor. Cutting temperature is elevated with spindle speed, thus promoting the softening of the matrix and inducing less delamination. For larger material removal rates associated with minimal delamination, higher spindle speed should be used when drilling GFRP.Jose Mathew et al. [12], experimentally investigated the effect of geometry of a trepanning tool on thrust and torque during the drilling of uni-directional glass fiber- reinforced plastic (UD-GFRP). Investigation was aimed at exploring the possibility of reducing the thrust and torque by using the concept of trepanning. An optimum geometry of the 
trepanning tool for drilling GFRP materials was obtained. Experiments are carried out with the analytical methods. This trepanning tool produced about 50\% less thrust and about $10 \%$ less torque as compared to twist drills. The holes were found to be of good and acceptable quality. The investigations have revealed that the performance of the trepanning tool is superior to that of conventional twist drills in terms of thrust, torque and hole quality. Fig. 5 shows comparison of the hole quality produced by the trepanning tool and twist drill.
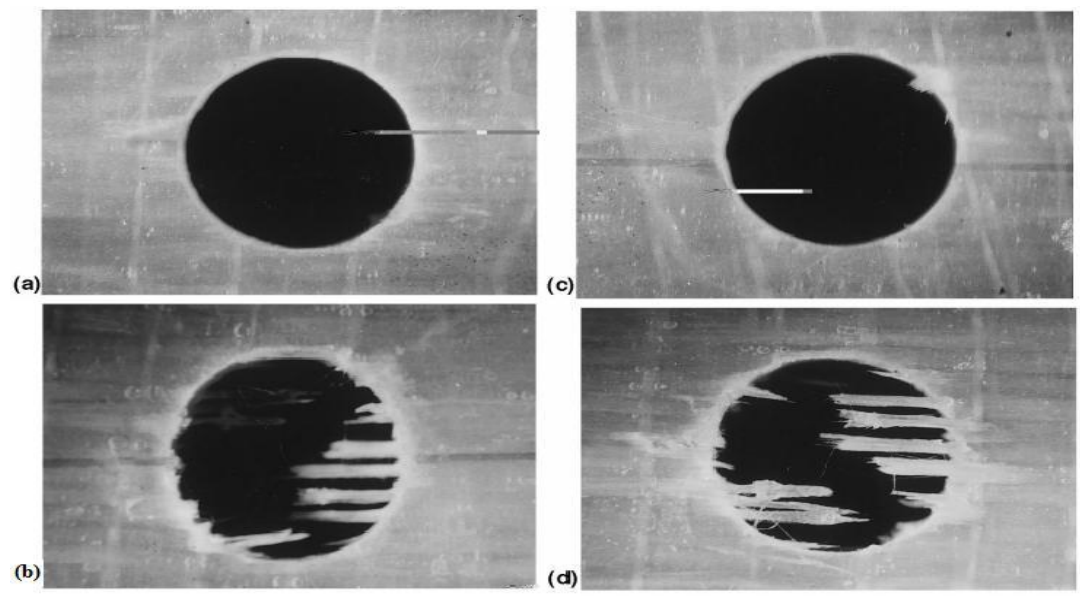

Fig. 5: comparison of the hole quality produced by the trepanning tool and twist drill (GFRP, 4-mm thick UD laminated; tool diameter $10 \mathrm{~mm}$; cutting speed $50 \mathrm{~m} / \mathrm{min}$; feed $0.2 \mathrm{~mm} / \mathrm{rev}$ ): (a) hole quality at entry with trepanning tool; (b) hole quality at entry with twist drill; (c) hole quality at exit with trepanning tool; and (d) hole quality at exit with twist drill) [12]Fig. 5 also shows from (a) to (d) the quality of holes at the entry and exit produced by the trepanning tool and the twist drill. Fiber pullout was almost absent in trepanned holes. It can be seen that the overall quality of the holes produced by trepanning tools is superior to those produced by the twist drills under identical cutting conditions. R. A. Kishore et al. [13], determined the optimal set of cutting parameters (cutting speed, the feed rate) and the drill point geometry that result in the maximum residual tensile strength in drilled unidirectional Glass Fiber Reinforced Epoxy composite using the Taguchi method. In Taguchiees methodology typical control factors for the drilling of unidirectional glass fiber reinforced epoxy composite include drill point geometry, feed rate and cutting speed. A L9 orthogonal array and signal-to-noise ratio were employed by Taguchi method. The term signal represents the desirable component of the output characteristics, which is close to its specific target value. The term noise represents the undesirable component and its measure of the variability of the output characteristics. The Taguchi method uses the signal-to-noise ratio $(\mathrm{S} / \mathrm{N})$ to express the scatter around a target value. The figure 6 shows relative effect of different parameters on residual tensile strength of the drilled glass fiber reinforced composite laminates. It can be seen that all the three parameters (drill point geometry, feed rate and cutting speed) have strong influence on residual strength of drilled composite. They established optimum levels of the drill point geometry, the cutting speed and feed rate for getting maximum residual tensile strength in drilled UD-GFRP laminates. They concluded that the drilling induced damage at higher cutting speeds severely affects the residual tensile strength of drilled laminates. Conformation tests were also carried out to verify the predicted optimal conditions. Values of estimation gain and conformation gain were found close each other.

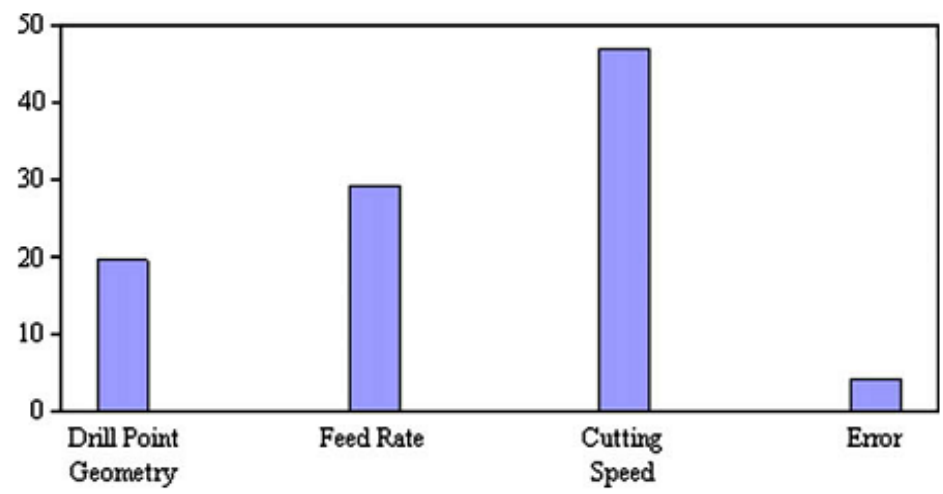

Fig. $6 \%$ contribution of process parameters on residual tensile strength [13] 
Tsao et al. [14], studied analytically and experimentally that delamination in drilling can be correlated to the thrust force of the drill. Early reference reported models of drilling-induced delamination, however, the effect of chisel edge length and pilot hole diameter on delamination is rarely discussed. Investigators have derived that with pre-drilled pilot hole, the delamination can be reduced significantly, and an optimal range of diameter of the pilot hole associated with chisel edge length is also derived. Tsao compared results of critical thrust force with pilot hole and without pilot hole which is shown in Fig.7

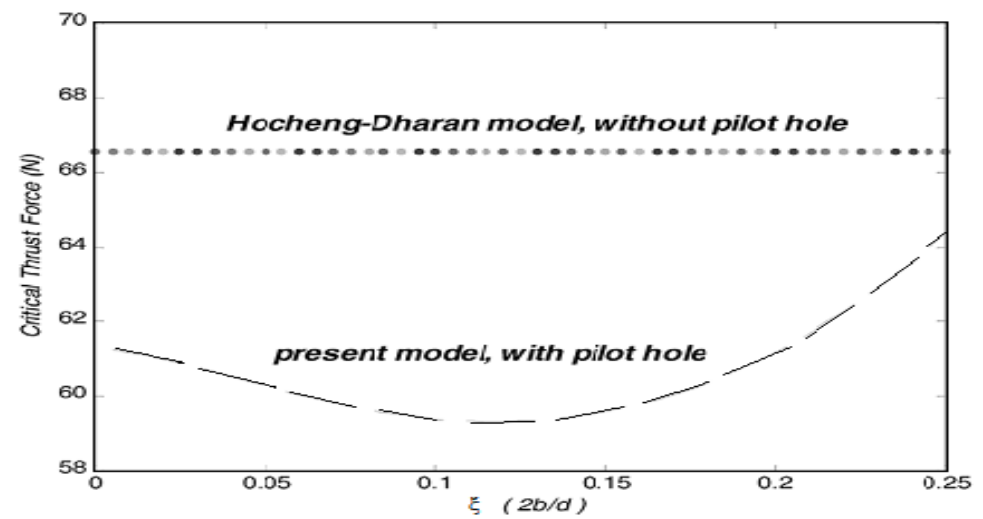

Fig. 7: Comparison of the critical thrust force predicted by C.C. Tsao and H. Hocheng model with pilot hole and by Hocheng and Dharan model without a pilot hole [13]

\section{The Conclusions of this review study are as follows}

\section{Conclusion}

1. After exhaustive literature survey and discussion, it is imperious that the Drilling on Composite material is very important in all industries as its benefits of high strength to weight ratio as especially where high precision is required.

2. Delamination factor is considered as very important as it directly related to quality of drilling, there are many factors are directly effected on delamination factor, as Many author has worked on different composite material as well as sandwich composite material by considering parameters like feed rate, point angle, chisel edge width, speed etc. but less found on Speed, feed \& Drill diameter as parameter for the study, effect of these parameters on delamination has not been notices a lot.

3. Not much of work has been done on correlation experimental results with percentage contribution of each factor on delamination.

4. So, in the present paper, it is intended to focus the Investigation on Drilling on GFRC material for enhancement of quality of dill hole. which is very beneficial to the manufacturing industry and reliefs engineers to choose appropriate parameters for particular applications.

\section{References}

[1]. P. Rahme, Y. Landon , F. Lachaud , R. Piquet, P. Lagarrigue, Delamination-free drilling of thick composite materials, Composites: Part A 72 (2015) 148-159.

[2]. Tom sunny, J.Babu, Jose Philip,Experimental Studies on Effect of Process Parameters on Delamination in Drilling GFRP Composites using Taguchi Method, Procedia Materials Science 6 ( 2014 ) 1131 - 1142

[3]. A.A. Patil, M.D. Shende, Experimental and Analytical Investigation of Drilling of Sandwich Composites: A Review, IOSR Journal of Mechanical and Civil Engineering, 2013, 6 (6),pp. 40-52. DOI: 10.9790/1684-0664052

[4]. S. Arul, L. Vijayaraghavan, S. K. Malhotra and R. Krishnamurthy, "Influence of tool material on dynamics of drilling of GFRP composite"; International Journal on Advance Manufacturing Technology, 29, 2006, pp 655-662.

[5]. Birhan Isik, Ergun Ekici, "Experimental investigations of damage analysis in drilling of woven glass fiber reinforced plastic composite"; International Journal of Advanced Manufacturing Technology, vol. 49, 2010, pp 861-869.

[6]. J. Campos Rubio, A.M. Abrao, P.E. Faria, A. Esteves Correia and J. Paulo Davim, "Effect of high speed in drilling of Glass Fiber Reinforced Plastic: Evaluation of the delamination factor"; International Journal of Machine Tools \& Manufacture, vol. 48, 2008, pp 715-720.

[7]. N.S. Mohan, A. Ramachandra, S.M. Kulkarni, Influence of process parameters on cutting force and torque during drilling of glass-fiber polyester reinforced composites, Composite Structures 71 (2005) 407-413

[8]. A. Velayudham, R. Krishnamurthy, T. Soundarapandian, Evaluation of drilling characteristics of high volume fraction fibre glass reinforced polymeric composite, International Journal of Machine Tools \& Manufacture 45 (2005) 399-406.

[9]. S. Arul - L. Vijayaraghavan - S.K. Malhotra $\bullet$ R. Krishnamurthy, Influence of tool material on dynamics of drilling of GFRP composites, Int J Adv Manuf Technol (2006) 29: 655-662, DOI 10.1007/s00170-005-2581-5. 
[10]. Birhan Işı1k \& Ergün Ekici, Experimental investigations of damage analysis in drilling of woven glass fiberreinforced plastic composites, Int J Adv Manuf Technol (2010) 49:861-869 DOI 10.1007/s00170-009-2440-x

[11]. J. Campos Rubio, A.M. Abrao, P.E. Faria, A. Esteves Correia, J. Paulo Davim, Effects of high speed in the drilling of glass fibre reinforced plastic: Evaluation of the delamination factor, International Journal of Machine Tools \& Manufacture 48 (2008) 715-720

[12]. Jose Mathew, N. Ramakrishnan and N. K. Naik, "Investigations into the effect of geometry of a trepanning tool on thrust and torque during drilling of GFRP composite"; Journal of Material Processing Technology, 91, 1999, pp 1-11.

[13]. R. A. Kishore, R. Tiwari, A. Dvivedi and I. Singh, "Taguchi analysis of the residual tensile strength after drilling in glass fiber reinforced epoxy composite"; Journal of Material and Design, 30, 2009, pp 2186-2190.

[14]. C.C. Tsao, H. Hocheng, "The effect of chisel length and associated pilot hole on delamination when drilling composite material"; International Journal of Machine Tools \& Manufacture, 43, 2003, pp 1087-1092. 